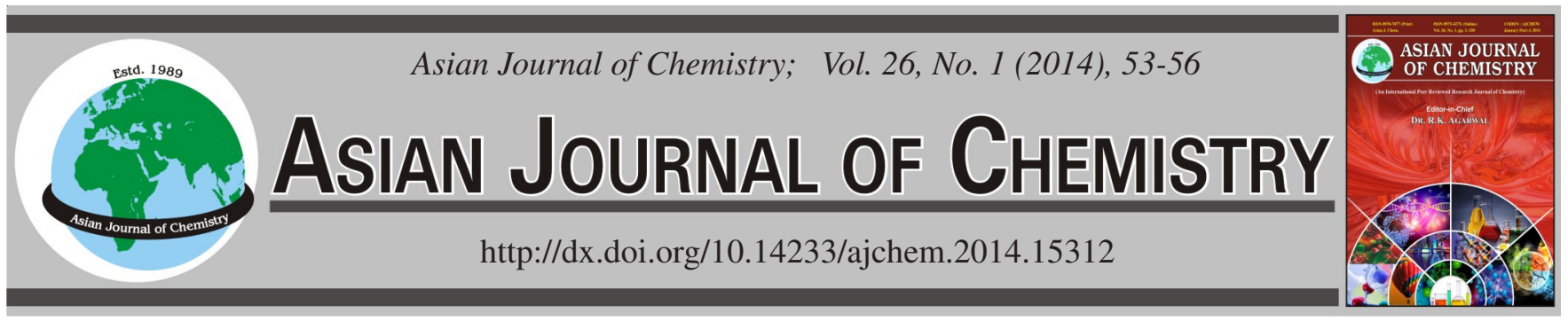

\title{
Preconcentration of Platinum Using Multi-Walled Carbon Nanotubes as Solid Phase Extraction Sorbent
}

\author{
Chunhua Yang, Zhanguie Huang ${ }^{*}$ and Zhongei Yang
}

Department of Chemistry, Yunnan University, Kunming 650091, P.R. China

*Corresponding author: Fax: +86 871 5032180; E-mail: zhjhuang@ynu.edu.cn

\begin{abstract}
A solid phase extraction and graphite furnace atomic absorption spectrometry for the determination of platinum with multi-walled carbon nanotubes as sorbent was studied. Platinum are preconcentrated on multi-walled carbon nanotubes in the form of $\left(\mathrm{L}_{2} \cdot \mathrm{H}_{3} \mathrm{O}^{+}\right)_{2} \mathrm{PtCl}_{6}{ }^{2-}$ ionpairs, where $\mathrm{L}=$ heptyl octyl sulfoxide and water was used as eluent. The effects of various parameters such as acidity, flow rate of sample, type of eluent, amount of adsorbent and interfering ions have been studied. The platinum in $100 \mathrm{~mL}$ solution can be concentrated to $2 \mathrm{~mL}$, representing an enrichment factor of 50 was achieved. The detection limit and quantification limit of the method were found to be 0.06 and $0.2 \mu \mathrm{g} \mathrm{L}{ }^{-1}$, respectively. The analytical results for the certified reference sample (GBW07292) was in a good agreement with the certified value. The relative standard deviation for ten replicate measurements of $1 \mu \mathrm{g} \mathrm{L} \mathrm{L}^{-1}$ platinum was $4.5 \%$. The proposed method was successfully applied to the extraction and determination of trace amount platinum in different samples.
\end{abstract}

Keywords: Solid phase extraction, Platinum, Heptyl octyl sulfoxide, Multi-walled carbon nanotubes.

\section{INTRODUCTION}

Platinum is mainly used in automobile exhaust catalytic converters and a catalyst in a wide variety of processes such as nitric acid production and petroleum re-forming. Platinum also finds applications in chemical and glass industries as cladding on account of anticorrosion properties and in electronic industry as material for electrodes, contacts and resistance wires. Another field of application of platinum is the manufacture of jewellery ${ }^{1-3}$. It has been shown that platinum in road dusts has increased after the introduction of vehicle catalyst. Platinum from road dusts, however, can be solubilized and enter waters, sediments, soils and the food chain. The health and safety executive lists: watering of the eyes, sneezing and eczematous as typical of platinum salt sensitization ${ }^{4,5}$. A critical evaluation of possible risks for human health can only be given if reliable analytical data are available.

The determination of platinum in environmental and biological samples is difficult for the high concentration of interfering matrix components and the low content of this metal in the most of the samples. Therefore, ultra-sensitive analytical methods are highly desirable. A separation/preconcentration step is often applied in order to remove matrix interferences and preconcentrate platinum to a level which can be reliably determined. Several methods have been reported for the separation and preconcentration of platinum, such as liquid-liquid extraction (LLE), high-performance liquid chromatography (HPLC) and solid-phase extraction (SPE) $)^{6-10}$. Among these techniques, solid-phase extraction is one of the most important preconcentration methodologies because of its advantages of high enrichment factor, high recovery, rapid phase separation, low cost, low consumption of organic solvents and the ability to combine with different detection techniques in on-line or off-line mode.

Carbon nanotubes (CNTs), the newest generation of carbon sorbents, have also great analytical potential as a solid phase extraction adsorbent for preconcentration and separation of metal ions ${ }^{11-16}$. The aim of this work is to combine solidphase extraction with graphite furnace atomic absorption spectrometry and develop a new method for the determination of platinum. In this method heptyl octyl sulfoxide (HOSO), which reacts with $\mathrm{Pt}(\mathrm{IV})$ forming a stable $\left[(\mathrm{HOSO})_{2} \cdot \mathrm{H}_{3} \mathrm{O}^{+}\right]_{2} \mathrm{PtCl}_{6}{ }^{2-}$ ion-pairs. Subsequently, water sample containing $\left[(\mathrm{HOSO})_{2} \cdot \mathrm{H}_{3} \mathrm{O}^{+}\right]_{2} \mathrm{PtCl}_{6}{ }^{2-}$ ion-pairs was passed through multiwalled carbon nanotubes (MWCNTs) cartridge. Platinum ion-pairs with $\mathrm{HOSO}$ were preconcentrated on MWCNTs. The $\left[(\mathrm{HOSO})_{2} \cdot \mathrm{H}_{3} \mathrm{O}^{+}\right]_{2} \mathrm{PtCl}_{6}{ }^{2-}$ ion-pairs adsorbed on MWCNTs cartridge was eluted with water. The levels of analyte ions in the samples were determined by the graphite furnace atomic absorption spectrometry. The optimum analytical conditions for the quantitative recoveries of platinum on MWCNTs adsorption resin were investigated. 


\section{EXPERIMENTAL}

A Z-2000 polarized Zeeman atomic absorption spectrophotometer (Hitachi High- Technologies Corpotation, Japan) was used in the studies. Hitachi hollow cathode lamps (HCL) were used for the determination of $\mathrm{Pt}(265.9 \mathrm{~nm})$ operated at 10 mA. High-purity argon (99.999\%, Messer Chemical Corpotation, Kunming, China) was used as the purge and sheath gas throughout at a flow rate of $200 \mathrm{~mL} \mathrm{~min}^{-1}$. The output signals were collected and processed with peak-height mode. Other operating conditions were carried out according recommendations of manufacturer.

Standard stock solutions of platinum (1000 mg L $\left.\mathrm{m}^{-1}\right)$ and the ore reference materials (GBW07292) were obtained from the National Institute of Standards (Beijing, China). Working standard solutions were obtained by appropriate dilution of the stock standard solution.

$0.5 \%(\mathrm{w} / \mathrm{v})$ solution of HOSO was prepared by dissolving appropriate amount of HOSO in ethanol. Ultra-pure water was used throughout. Pipettes and vessels in the experiments were kept in $10 \%$ nitric acid for at least $24 \mathrm{~h}$ and subsequently washed four times with ultra-pure water. All other reagents used were of the highest available purity and of at least analytical reagent grade. Ultra-pure water of resistivity $18 \mathrm{M} \Omega \mathrm{cm}$ obtained from a UPHW purification device (Ulupure Co. Shanghai, China) was used to prepare all the solutions.

Heptyl octyl sulfoxide (HOSO) was obtained from Yunnan Petrochemical Company. Multi-walled carbon nanotubes (MWCNTs) was purchased from Shenzhen Nanotech Port Co. Ltd (Shenzhen, China).

Preconcentration procedure: An off-line column procedure was applied for the preconcentration process. The Teflon column was $8 \mathrm{~cm}$ long and $0.8 \mathrm{~cm}$ in diameter. The $2 \mu \mathrm{m}$ of sieve plate was placed to prevent loss of the resin beads during sample loading. Then, $200 \mathrm{mg}$ of MWCNTs was poured into the column. The resin bed was washed with plenty of ultra-pure water until neutral $\mathrm{pH}$ and subsequently reused. The method was tested with model solutions before its application to real samples. $100 \mathrm{~mL}$ of solutions containing 20-400 ng platinum, $45 \mathrm{~mL}$ of $12 \mathrm{~mol} \mathrm{~L}^{-1}$ hydrochloric acid solution and $5 \mathrm{~mL}$ of $0.5 \%$ HOSO was passed through the

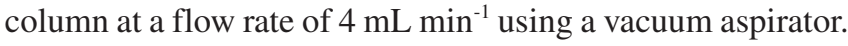
The retained platinum ions were eluted from the column by $2 \mathrm{~mL} \mathrm{H}_{2} \mathrm{O}$ and the concentrations of platinum ions were determined by GFAAS. A blank solution was also run under the same conditions without adding the analytes.

Sample preparation: The developed method has been successfully applied to the determination of platinum in ore reference materials, environmental and biological samples.

Twelve grams of ore reference materials were transferred into a porcelain crucible and roasted for $2 \mathrm{~h}$ in a muffle furnace at $600{ }^{\circ} \mathrm{C}$. After roasting, the sample was transferred to 500 $\mathrm{mL}$ glass beaker and $120 \mathrm{~mL}$ of freshly prepared aqua regia was added to sample. One gram of $\mathrm{NaCl}$ was added to stabilize the platinum chloride complex during evaporation on a hot plate. The beaker was covered with a watch glass and heated on a hot plate. Heating was continued for at least $2 \mathrm{~h}$ and enough aqua regia was added at regular intervals to maintain the free acid level at about $1 \mathrm{~cm}$ above the sample level. The watch glass was removed and the content was evaporated slowly until the residue became nearly dry. Then, $20 \mathrm{~mL}$ of $6 \mathrm{~mol} \mathrm{HCl}$ was added and the mixture was heated to dryness. This last step was repeated twice to ensure total elimination of $\mathrm{HNO}_{3}$. Afterwards, sample solution was cooled and filtered using Whatman No.1 filter paper (pore size, $11 \mu \mathrm{m}$ ). The residue was washed with minimum amounts of $0.1 \mathrm{~mol} \mathrm{~L}^{-1} \mathrm{HCl}$. The final residue was discarded and the filtrate was then dissolved and diluted to $100 \mathrm{~mL}$ with distilled water. Finally, platinum in ore sample was determined by the proposed method.

The lentil, pea and lettuce sample were collected from a urban vegetable garden in Kunming. The sample was washed with tap water and distilled water. Then, dried at $110^{\circ} \mathrm{C} .8 \mathrm{~g}$ of sample was weighted in a beaker and $80 \mathrm{~mL}$ of concentrated nitric acid was added. The mixture was gently heated on a hot plate for at least $2 \mathrm{~h}$ and enough concentrated nitric acid was added at regular intervals. After cooling to room temperature, $25 \mathrm{~mL}$ of concentrated $\mathrm{H}_{2} \mathrm{O}_{2}$ was added into the beaker. The mixture was again evaporated near to dryness. Then, $30 \mathrm{~mL}$ of $6 \mathrm{~mol} \mathrm{HCl}$ was added and the mixture was heated to dryness. This last step was repeated twice to ensure total elimination of $\mathrm{HNO}_{3}$. Then, $20 \mathrm{~mL}$ of $1 \mathrm{~mol} \mathrm{~L}^{-1} \mathrm{HCl}$ was added to the beaker and the solution was warmed until clear solution was obtained. The solid residue was filtered using Whatman No. 1 filter paper (pore size, $11 \mu \mathrm{m}$ ). The final residue was discarded and the filtrate was then diluted to $100 \mathrm{~mL}$ with distilled water.

For water samples, river water sample was collected from Baoxiang river (Kumming, P.R. China). Tap water sample was freshly collected from our laboratory. The water samples was immediately acidified by adding several drops of nitric acid and filtrated with $0.45 \mu \mathrm{m}$ filter. Then the preconcentration procedure given above was applied to the samples.

Graphite furnace atomic absorption spectrometry analysis: The GFAAS analysis condition is listed in Table-1. For samples analysis, a $20 \mu \mathrm{L}$ aliquot of the samples or standard solution was injected into the graphite cuvette for the GFAAS determination. The atomic absorption signals were measured with the Zeeman background corrector in operation. The measurement was repeated three times and the obtained signals were averaged.

\begin{tabular}{lc}
\multicolumn{2}{c}{ TABLE-1 } \\
\multicolumn{1}{c}{ SETTING OF ANALYTICAL CONDITIONS } \\
\hline \multicolumn{1}{c}{ Analytical condition } & Pt \\
\hline Calculation mode & Peak height \\
Wavelength $(\mathrm{nm})$ & 265.9 \\
Slit width $(\mathrm{nm})$ & 0.4 \\
Time constant $(\mathrm{s})$ & 0.1 \\
Lamp current $(\mathrm{mA})$ & $10 \mathrm{~mA}$ \\
Cuvette type & Pyro tube HR \\
Dry start/end temp $\left({ }^{\circ} \mathrm{C}\right)$ & $80 / 140$ \\
Dry ramp time $(\mathrm{S})$ & 40 \\
Ash start/end temp $\left({ }^{\circ} \mathrm{C}\right)$ & $800 / 800$ \\
Ash ramp time $(\mathrm{S})$ & 20 \\
Atomize start/end temp $\left({ }^{\circ} \mathrm{C}\right)$ & $2700 / 2700$ \\
Atomize hold time $(\mathrm{S})$ & 5 \\
Clean start/end temp $\left({ }^{\circ} \mathrm{C}\right)$ & $2800 / 2800$ \\
Clean hold time $(\mathrm{S})$ & 4 \\
Carrier gas $\left(\mathrm{mL}\right.$ min $\left.{ }^{-1}\right)$ & 30 \\
Sample injection volume $(\mu \mathrm{L})$ & 20 \\
\hline
\end{tabular}




\section{RESULTS AND DISCUSSION}

Effect of acidity: The acidity of the sample solution is one of the important factors affecting the formation of $\left[(\mathrm{HOSO})_{2} \cdot \mathrm{H}_{3} \mathrm{O}^{+}\right]_{2} \mathrm{PtCl}_{6}{ }^{2-}$ ion-pairs and the subsequent solid phase extraction. According to the results, quantitative recoveries (95\%) for analytes were obtained in the presence of $\mathrm{HCl}$ in the concentration range: $4-6 \mathrm{~mol} \mathrm{~L}^{-1}$. Thus $45 \mathrm{~mL} 12 \mathrm{~mol} \mathrm{~L}^{-1}$ $\mathrm{HCl}$ solutions was recommended to control acidity.

Influences of HOSO amount: In order to determine the amounts of HOSO required for quantitative recovery for platinum(IV), the proposed method was applied. Changing the HOSO amounts $(0.5 \%$ solution $)$ in the range of $1-10 \mathrm{~mL}$. The results showed that the recovery values of the analyte platinum(IV) were increased with increasing amounts of HOSO added. The recovery reaches a constant value with at least $4 \mathrm{~mL}$ of $0.5 \%$ HOSO solution used. On this basis, studies were carried out at HOSO amounts of $5 \mathrm{~mL}$. This amount of HOSO is enough for the separation and preconcentration procedure because of the very low level of the investigated platinum (IV) concentrations in real samples.

Effects of amount of multi-walled carbon nanotubes: Also the amounts of solid phase extraction material are another important factor on the column studies for the quantitative recoveries of $\left[(\mathrm{HOSO})_{2} \cdot \mathrm{H}_{3} \mathrm{O}^{+}\right]_{2} \mathrm{PtCl}_{6}{ }^{2-}$ ion-pairs. The effect of the amount of MWCNTs on the sorption of metal ions was examined in the range of $100-400 \mathrm{mg}$. The results demonstrated that, quantitative recoveries ( $>95 \%$ ) of platinum was observed in the range of $150-250 \mathrm{mg}$. Above $300 \mathrm{mg}$ the recoveries were below $95 \%$ with $2.0 \mathrm{~mL}$ of the eluent. Therefore, in the proposed procedure, $200 \mathrm{mg}$ of MWCNTs is recommended.

Effect of flow rate of sample solution: The influence of flow rate on the adsorption of $\left[(\mathrm{HOSO})_{2} \cdot \mathrm{H}_{3} \mathrm{O}^{+}\right]_{2} \mathrm{PtCl}_{6}^{2-}$ ion-pairs was also studied. Flow rate in the range of $2-5 \mathrm{~mL} \mathrm{~min}^{-1}$ had no significant effect on the recoveries of platinum(IV). Therefore, in the proposed procedure, $4 \mathrm{~mL} \mathrm{~min}^{-1}$ flow rate is recommended.

Among several media investigated as eluent $\left(\mathrm{H}_{2} \mathrm{O}, \mathrm{HNO}_{3}\right.$, ethanol, methanol acetone, thiourea), only $\mathrm{H}_{2} \mathrm{O}$ showed satisfactory elution characteristics. $2 \mathrm{~mL}$ of $\mathrm{H}_{2} \mathrm{O}$ provided quantitative recovery $(>95 \%)$ and reproducibility. The elution was performed in the opposite direction to avoid the clogging of the column. The platinum in $100 \mathrm{~mL}$ solution can be concentrated to $2 \mathrm{~mL}$, representing an enrichment factor of 50 was achieved.

Effect of interfering ions on recovery: The effects of common coexisting ions in the samples on the extraction recovery of platinum were studied. In these experiments, 100 $\mathrm{mL}$ solutions contains $2 \mu \mathrm{g} \mathrm{L}^{-1}$ of platinum and various amounts of interfering ions were treated according to the recommended procedure. The tolerance limit was set, as the diverse ion amount require causing $\pm 5 \%$ error in the determination of platinum. The results obtained are given in Table- 2 .

Loading capacity: To $0.1 \mathrm{~g}$ MWCNTs was placed in the conical flasks. Stock solution of platinum(IV) and HOSO were added to the flask. $\mathrm{HCl}$ in the concentration range: Acidity of the solution was adjusted to 4-6 mol L-1 using $12 \mathrm{~mol} \mathrm{~L}^{-1} \mathrm{HCl}$ solution. After shaking for $3 \mathrm{~h}$, the mixture was filtered. Concentration of Pt(IV) was measured by GFAAS. The loading capacity of MWCNTs was $9.5 \mathrm{mg} \mathrm{g}^{-1}$ for platinum.
TABLE-2

TOLERANCE OF FOREIGN IONS IN THE DETERMINATION OF $2.0 \mu \mathrm{g} \mathrm{L}^{-1}$ PLATINUM

\begin{tabular}{cccc} 
Interferent & Added as & Concentration $\left(\mathrm{mg} \mathrm{L}^{-1}\right)$ & Recovery (\%) \\
\hline $\mathrm{Co}^{2+}$ & $\mathrm{CoSO}_{4}$ & 800 & 97 \\
$\mathrm{Fe}^{3+}$ & $\mathrm{FeCl}_{3}$ & 750 & 96 \\
$\mathrm{Ni}^{2+}$ & $\mathrm{NiSO}_{4}$ & 700 & 98 \\
$\mathrm{Zn}^{2+}$ & $\mathrm{ZnSO}_{4}$ & 700 & 101 \\
$\mathrm{Cu}^{2+}$ & $\mathrm{CuSO}_{4}$ & 600 & 95 \\
$\mathrm{~Pb}^{2+}$ & $\mathrm{PbSO}_{4}$ & 600 & 102 \\
$\mathrm{Pd}^{2+}$ & {$\left[\mathrm{PdCl}_{4}\right]^{2-}$} & 200 & 96 \\
$\mathrm{Ir}^{4+}$ & {$\left[\mathrm{IrCl}_{6}\right]^{2-}$} & 100 & 97 \\
$\mathrm{Rh}^{3+}$ & {$\left[\mathrm{RhCl}_{6}\right]^{3-}$} & 100 & 101 \\
\hline
\end{tabular}

Calibration curve and detection limit: Using optimized conditions of preconcentration, calibration curve was prepared for platinum. The limit of detection (LOD) value (blank $+3 \sigma$ ) and limit of quantification (LOQ) value (blank $+10 \sigma)$, where $\sigma$ is standard deviation of blank determination $(n=12)$, were found to be 0.06 and $0.2 \mu \mathrm{g} \mathrm{L}{ }^{-1}$, respectively. The results were also shown in Table-3. MWCNTs can be reused at least 60 times.

\begin{tabular}{|c|c|}
\hline \multicolumn{2}{|c|}{$\begin{array}{c}\text { TABLE-3 } \\
\text { ANALYTICAL CHARACTERISTICS } \\
\text { OF THE PROPOSED METHOD }\end{array}$} \\
\hline Parameter & Analytical feature \\
\hline Regression equation $\left(\mathrm{C}_{\mathrm{Pt}} \text { in } \mu \mathrm{g} \mathrm{L}^{-1}\right)^{\mathrm{a}}$ & $\begin{aligned} \mathrm{A}=1.26 & \times 10^{-3} \mathrm{C}+3.26 \\
& \times 10^{-3}\end{aligned}$ \\
\hline Linear range $\left(\mu \mathrm{g} \mathrm{L}^{-1}\right)^{\mathrm{a}}$ & $10-200.00$ \\
\hline Correlation coefficient & 0.9993 \\
\hline Enrichment factor & 50 \\
\hline $\begin{array}{l}\text { The relative standard deviation } \\
\left(1.0 \mu \mathrm{L} \mathrm{L}^{-1}, \mathrm{n}=10\right)^{\mathrm{b}}\end{array}$ & 4.5 \\
\hline $\begin{array}{l}\text { Detection limit }\left(\mu \mathrm{g} \mathrm{L}^{-1}\right)^{\mathrm{b}} \\
(\mathrm{LOD}=\text { bland }+3 \sigma, \mathrm{n}=12)\end{array}$ & 0.06 \\
\hline $\begin{array}{l}\text { Quantification limit }\left(\mu \mathrm{g} \mathrm{L}^{-1}\right)^{\mathrm{b}} \\
(\mathrm{LOQ}=\text { bland }+10 \sigma, \mathrm{n}=12)\end{array}$ & 0.2 \\
\hline
\end{tabular}

Applications of the presented procedure: In order to establish the validity of the proposed procedure, the method has been applied to the determination of $\mathrm{Pt}$ in the ore reference materials samples (GBW07292). The results were given in Table-4.

TABLE-4

DETERMINATION OF Pt $\left(\mathrm{ng} \mathrm{g}^{-1}\right)$ IN THE CERTIFIED REFERENCE MATERIALS AFTER APPLICATION OF THE PRESENTED PROCEDURE $(\mathrm{n}=5)$

Sample $\quad$ Certified value $\left(\mathrm{ng} \mathrm{g}^{-1}\right) \quad$ Our value $\left(\mathrm{ng} \mathrm{g}^{-1}\right)$

$\begin{array}{lll}\text { GBW07292 } & 20 \pm 4 & 21 \pm 3\end{array}$

The proposed method was applied to determine of platinum in water and biological samples. The results for water samples are shown in Table-5 and biological samples are given in Table-6. In all cases the spiked recoveries confirmed the reliability of the proposed method. The results indicate that the recoveries in the range of 96-103\% are reasonable well for trace analysis.

\section{Conclusion}

The present study demonstrates the use of multi-walled carbon nanotubes (MWCNTs) as a new sorbent in the preconcentration of platinum ions in different matrices. The method 


\begin{tabular}{|c|c|c|c|}
\hline \multicolumn{4}{|c|}{$\begin{array}{c}\text { TABLE-5 } \\
\text { DETERMINATION OF PLATINUM }\left(\mu \mathrm{g} \mathrm{L} \mathrm{L}^{-1}\right) \\
\text { IN WATER SAMPLES }(\mathrm{n}=5)\end{array}$} \\
\hline Sample & $\begin{array}{l}\text { Added } \\
\left(\mu \mathrm{g} \mathrm{L}^{-1}\right)\end{array}$ & $\begin{array}{l}\text { Found }{ }^{\mathrm{a}} \text { by present } \\
\text { method }\left(\mu \mathrm{g} \mathrm{L}^{-1}\right)\end{array}$ & $\begin{array}{l}\text { Recovery } \\
(\%)\end{array}$ \\
\hline \multirow{2}{*}{ River water } & 0 & BDL & - \\
\hline & 10 & $10.3 \pm 0.1$ & 103.0 \\
\hline \multirow{2}{*}{ Tap water } & 0 & BDL & - \\
\hline & 10 & $9.6 \pm 0.2$ & 96.0 \\
\hline \multicolumn{4}{|c|}{-: not determined; BDL, below the detection limit; ${ }^{\mathrm{a}}$ Mean \pm SD. } \\
\hline \multicolumn{4}{|c|}{$\begin{array}{c}\text { TABLE-6 } \\
\text { DETERMINATION OF PLATINUM }\left(\mathrm{ng} \mathrm{g}^{-1}\right) \\
\text { IN BIOLOGICAL SAMPLES }(\mathrm{n}=5)\end{array}$} \\
\hline Sample & $\begin{array}{l}\text { Added } \\
\left(\mathrm{ng} \mathrm{g}^{-1}\right)\end{array}$ & $\begin{array}{l}\text { Found }{ }^{\mathrm{a}} \text { by present } \\
\text { method }\left(\mathrm{ng} \mathrm{g}^{-1}\right)\end{array}$ & $\begin{array}{c}\text { Recovery } \\
(\%)\end{array}$ \\
\hline \multirow{2}{*}{ Lentil } & 0 & BDL & - \\
\hline & 10 & $10.2 \pm 0.2$ & 102.0 \\
\hline \multirow{2}{*}{ Pea } & 0 & BDL & \\
\hline & 10 & $9.8 \pm 0.3$ & 98.0 \\
\hline \multirow{2}{*}{ Lettuce } & 0 & BDL & - \\
\hline & 10 & $9.7 \pm 0.2$ & 97.0 \\
\hline
\end{tabular}

is a simple, sensitive, precise, reliable and accurate technique. The advantages of this method is its selective adsorption in a wide range of sample acidity $(4-6 \mathrm{M} \mathrm{HCl})$. The method is also low cost. Instead of the use of fresh solvent as an extracting phase for each sample, the reusability of MWCNTs was as high as greater than 60 cycles without any loss in its sorption behaviour. The tolerance limits of interfering ions on the recovery of platinum ions are quite high. The results acquired from the analyses of the standard reference material confirmed the reliability of the method. The proposed method possesses lower limit of detection and higher enrichment factor, which makes it suitable for the determination of trace amount of platinum in environmental and biological samples.

\section{ACKNOWLEDGEMENTS}

This work was supported by the National Natural Science Foundation of China (51264038), Key Natural Science Foundation of China (U0937601), Development Program of China (2011AA03A405D) and Science and Technology Support Program of China (2008BAB32B10).

\section{REFERENCES}

1. M. Chappuy, E. Caudron, A. Bellanger and D. Pradeau, J. Hazard. Mater, 176, 207 (2010).

2. C.B. Ojeda, F. Sanchez-Rojas, J.M.C. Pavon and A. Garcia de Torres, Anal. Chim. Acta, 494, 97 (2003).

3. A. Lasztity, A. Kelko-Levai, K. Zih-Perenyi and I. Varga, Talanta, 59, 393 (2003)

4. M. Muzikar, C. Fontas, M. Hidalgo, J. Havel and V. Salvado, Talanta, 70, 1081 (2006).

5. C.B. Ojeda, F.S. Rojas and J.M.C. Pavón, Food Control, 17, 365 (2006).

6. L.M. Zhou, J.H. Liu and Z.R. Liu, J. Hazard. Mater., 172, 439 (2009).

7. Y.W. Wu, Z.C. Jiang, B. Hu and J.K. Duan, Talanta, 63, 585 (2004).

8. B. Godlewska-Zylkiewicz, Spectrochim. Acta B, 58, 1531 (2003).

9. X.P. Ge, I. Wendler, P. Schramel and A. Kettrup, React. Funct. Polym., 61, 1 (2004).

10. M. Gurung, B.B. Adhikari, S. Morisada, H. Kawakita, K. Ohto, K. Inoue and S. Alam, Bioresour. Technol., 129, 108 (2013).

11. K. Pyrzynska, Anal. Chim. Acta, 741, 9 (2012).

12. S. Ghaseminezhad, D. Afzali and M.A. Taher, Talanta, 80, 168 (2009).

13. M. Tuzen and M. Soylak, J. Hazard. Mater, 147, 219 (2007).

14. Z.P. Zang, Z. Hu, Z.H. Li, Q. He and X. Chang, J. Hazard. Mater, 172, 958 (2009)

15. A. Duran, M. Tuzen and M. Soylak, J. Hazard. Mater., 169, 466 (2009).

16. C.G. Yuan, Y. Zhang, S.P. Wang and A. Chang, Microchim. Acta, 173, 361 (2011) 